Reihe Ökonomie

Economics Series

\title{
A Hierarchical Procedure for the Combination of Forecasts ${ }^{*}$
}

\author{
Mauro Costantini, Carmine Pappalardo
}

"This is a revised version of Working Paper 228, Economics Series, October 2008, which includes some changes. The most important change regards the reference of Kisinbay (2007), which was not reported in the previous version. The hierarchical procedure proposed in the paper is based on the approach of Kisinbay (2007), but some modifications of that approach are provided." 

Reihe Ökonomie Economics Series

\section{A Hierarchical Procedure for the Combination of Forecasts}

Mauro Costantini, Carmine Pappalardo

June 2009

Institut für Höhere Studien (IHS), Wien

Institute for Advanced Studies, Vienna 


\section{Contact:}

\section{Mauro Costantini}

Department of Economics

University of Vienna BWZ

Bruenner Str. 72

1210 Vienna, Austria

囱: $+43 / 1 / 4277-37478$

fax: +43/1/4277-37498

email: mauro.costantini@univie.ac.at

Carmine Pappalardo

ISAE, Institute for Studies and Economic Analysis

Rome

Founded in 1963 by two prominent Austrians living in exile - the sociologist Paul F. Lazarsfeld and the economist Oskar Morgenstern - with the financial support from the Ford Foundation, the Austrian Federal Ministry of Education and the City of Vienna, the Institute for Advanced Studies (IHS) is the first institution for postgraduate education and research in economics and the social sciences in Austria. The Economics Series presents research done at the Department of Economics and Finance and aims to share "work in progress" in a timely way before formal publication. As usual, authors bear full responsibility for the content of their contributions.

Das Institut für Höhere Studien (IHS) wurde im Jahr 1963 von zwei prominenten Exilösterreichern dem Soziologen Paul F. Lazarsfeld und dem Ökonomen Oskar Morgenstern - mit Hilfe der FordStiftung, des Österreichischen Bundesministeriums für Unterricht und der Stadt Wien gegründet und ist somit die erste nachuniversitäre Lehr- und Forschungsstätte für die Sozial- und Wirtschaftswissenschaften in Österreich. Die Reihe Ökonomie bietet Einblick in die Forschungsarbeit der Abteilung für Ökonomie und Finanzwirtschaft und verfolgt das Ziel, abteilungsinterne Diskussionsbeiträge einer breiteren fachinternen Öffentlichkeit zugänglich zu machen. Die inhaltliche Verantwortung für die veröffentlichten Beiträge liegt bei den Autoren und Autorinnen. 


\section{Abstract}

This paper proposes a strategy to increase the efficiency of forecast combination. Given the availability of a wide range of forecasts for the same variable of interest, our goal is to apply combining methods to a restricted set of models. To this aim, a hierarchical procedure based on an encompassing test is developed. Firstly, forecasting models are ranked according to a measure of predictive accuracy (RMSFE). The models are then selected for combination such that each forecast is not encompassed by any of the competing forecasts. Thus, the procedure aims to unit model selection and model averaging methods. The robustness of the procedure is investigated in terms of the relative RMSFE using ISAE (Institute for Studies and Economic Analyses) short-term forecasting models for monthly industrial production in Italy.

\section{Keywords}

Combining Forecasts; Econometric Models; Evaluating Forecasts; Models Selection, Time series

\section{JEL Classification}

C32, C53 


\section{Comments}

The first draft of this paper was mostly prepared while Mauro Costantini was working as a postdoctorate researcher at ISAE. The authors would like to thank Michael P. Clements and Robert Kunst for their very useful suggestions. The authors would also like to thank the partecipants at the 28th annual International Symposium on Forecasting, Nice 2008. None of them is responsible for any remaining errors. The opinions expressed in this paper are solely the responsibility of the authors and should not be interpreted as reflecting the views of ISAE or its staff. 


\section{Contents}

1 Introduction 1

2 Forecast encompassing and RMSFE 2

3 Forecast encompassing and combining methods 3

4 Forecasting models 5

5 Empirical results $\quad 7$

6 Conclusions 9

$\begin{array}{ll}\text { References } & 9\end{array}$

$\begin{array}{ll}\text { Figure and Tables } & 11\end{array}$ 



\section{Introduction}

Forecast combination is often used to improve forecast accuracy. A linear combination of two or more predictions may often yield more accurate forecasts than using a single prediction to the extent that the component forecasts contain useful and independent information (Newbold and Harvey, 2002). To generate independent forecasts two alternative methods can be followed. One is to examine different data, and the other is to use different forecasting methods. On the one hand, the use of several sources of data can add useful information and can also adjust for biases. On the other hand, forecasting combining methods can reduce errors arising from faulty assumption, bias, or mistake data.

This paper considers a hierarchical procedure to increase the efficiency of forecasting combining methods is provided. The procedure is based on the approach proposed by Kisinbay (2007), but in this paper paper the RMSFE encompassing testing approach is discussed to show under which conditions the encompassing test developed by Harvey, Leybourne and Newbold (1998, hereafter HLN) can be used to check for forecast encompassing in one direction, and a multiple encompassing test (Harvey and Newbold, 2000) is used to assess the robustness of the model selection strategy.

The procedure consists of several steps. Firstly, the overall forecasts are ranked using RMSFE measure. The forecasting models are then selected for combination using the HLN encompassing test. Thus, the hierarchical approach aims to unit model selection and model averaging methods. Larger weights are assigned to the models with higher forecasting performance and which add information not covered by other models. Estimated forecasts with lower accuracy and that are encompassed by all the other models are discarded as their weights will be insignificant (Hendry and Clements, 2004). For these reasons, the hierarchical procedure can be considered as an alternative to the optimal combination method based on the variance-covariance matrix of forecasting errors. The hierarchical algorithm is aimed at selecting a given model $M_{1}$ with greater forecasting accuracy vis a vis the rival $M_{2}$ only if the former presents a greater informative content. In general terms, if a given model has a lower RMSFE than the other forecasting models, the sufficient condition to minimize its RMSFE is to verify that it encompasses all the other competing models (Ericsson, 1992). For these reasons, the HLN test is only performed in one direction. The model selection through the hierarchical procedure operates as described below. Consider 3 models, $M_{1}, M_{2}$ and $M_{3}$, where RMSFE $1<\mathrm{RMSFE}_{2}<\mathrm{RMSFE}_{3}$. In the first step, $M_{1}$ (the first best model in terms of forecast accuracy) is compared with $M_{2}$ and $M_{3}$ using the encompassing test. If $M_{1}$ encompasses $M_{2}$ but not $M_{3}$, then $\mathrm{RMSFE}_{1}<\mathrm{RMSFE}_{2} . M_{1}$ is not the only retained forecast. In a successive step $M_{2}$ (the second best model) is tested against $M_{3}$. If $M_{2}$ does encompass $M_{3}$, the latter is discarded. On the other hand, if $M_{2}$ does not encompass $M_{3}$, no model selection occurs through the algorithm and forecast averaging is performed using all the forecasting models.

The robustness of the procedure is investigated in the last step using the relative RMSFE, computed as a ratio between the RMSFE of the hierarchical forecast and the RMSFE from both the best single model and the combination of overall forecasts. When the relative RMSFE is significantly less than one, the hierarchical forecast outperforms the competing models.

The procedure here considered is applied to Italian monthly industrial produc- 
tion. We exploit several short-term forecasting models currently used at ISAE (Institute for Studies and Economic Analyses) to obtain forecasts up to six-steps ahead, both in a recursive and rolling regression framework. Our findings show that forecasts deriving from the hierarchical procedure outperform in terms of RMSFE those obtained by both the best single forecasting model and combining overall models. Clear-cut evidence is obtained using simpler averaging methods.

This paper is organized as follows. Section 2 discusses the conditions under which HLN test can be used to check for forecast encompassing in one direction. Section 3 presents the hierarchical procedure. Section 4 describes the seven ISAE forecasting models. Section 5 presents empirical results. Section 6 concludes.

\section{Forecast encompassing and RMSFE}

In this section the RMSFE encompassing testing procedure is reviewed to show the conditions under which the HLN test can be used to check for forecast encompassing in one direction. To improve the detection of the predictive ability across non-nested models, Ericsson (1992) shows that the forecast encompassing test is a sufficient condition for RMSFE dominance, i.e. to minimize RMSFE of a given model. The starting point is to consider two alternative non-nested linear models for the same dependent variable $y_{t}$, both estimated over the sample period $[1, T]$ :

$$
\begin{aligned}
& M_{1}: y_{t}=\delta_{1}^{\prime} z_{1 t}+\nu_{1 t}, \\
& M_{2}: y_{t}=\delta_{2}^{\prime} z_{2 t}+\nu_{2 t},
\end{aligned}
$$

where $z_{1 t}$ and $z_{2 t}$ do not have regressors in common and are linked by the relation $z_{1 t}=\Pi z_{2 t}+\varepsilon_{1 t}$. Substituting the expression for $z_{1 t}$ into (1), equation (2) is re-parameterized with the following restrictions:

$$
\begin{aligned}
& \delta_{2}^{\prime}=\left(\delta_{1}^{\prime} \Pi\right), \\
& \nu_{2, t}=\nu_{1, t}+\delta_{1}^{\prime} \varepsilon_{1, t} .
\end{aligned}
$$

Assuming that the forecasts from models (1) and (2) are $\hat{y}_{1 j}=\delta_{1}^{\prime} z_{1 j}$ and $\hat{y}_{2 j}=$ $\delta_{2}^{\prime} z_{2 j},(j=\mathrm{T}+1, \ldots, \mathrm{T}+n)$, restriction (3) (forecast-model encompassing) implies that $z_{2 j}$ has no power to explain the forecast error given $z_{1 j}$. This is equivalent to testing for $\gamma=0$ in the equation $y_{j}=\delta_{1}^{\prime} z_{1 j}+\gamma z_{2 j}+\nu_{1 j}$. From restriction (4), we obtain

$$
\mathrm{E}\left(y_{j}-\hat{y}_{2 j}\right)^{2}=\mathrm{E}\left(y_{j}-\hat{y}_{1 j}\right)^{2}+\delta_{1}^{\prime} \Omega \delta_{1},
$$

where $\mathrm{E}\left(y_{j}-\hat{y}_{1 j}\right)^{2}$ is the RMSFE of model $1, \mathrm{E}\left(y_{j}-\hat{y}_{2 j}\right)^{2}$ is the RMSFE of model 2 and $\Omega=\mathrm{E}\left(\varepsilon_{1 j}^{\prime} \varepsilon_{1 j}\right)$. Testing this hypothesis is equivalent to testing for $\alpha=0$ (forecast encompassing) in the equation

$$
y_{j}=\delta_{1}^{\prime} z_{1 j}+\alpha \hat{y}_{2 j}+\nu_{1 j} .
$$

As shown in Ericsson (1992), the sufficient condition for this is that $\gamma=0$. Furthermore, this implies that $\Omega$ is a positive definite matrix, so that $\mathrm{RMSFE}_{1}<$ 
$\mathrm{RMSFE}_{2}$ (RMSFE dominance). From the discussion above, the sufficient condition to minimize the RMSFE of a given model is to verify that it encompasses all the other competing models. This implies using the encompassing test in only one direction.

In the HLN test, if the forecasts from model 1 encompass the forecasts from model 2 , then the covariance between $e_{1 t}$ and $e_{1 t}-e_{2 t}$ will be negative or zero, where $e_{1 t}$ and $e_{2 t}$ are the two sets of forecast errors obtained from using the two models. The alternative hypothesis is that the forecasts from model 1 do not encompass those from model 2 , in which case the covariance between $\mathrm{e}_{1 \mathrm{t}}$ and $\mathrm{e}_{1 \mathrm{t}}-\mathrm{e}_{2 \mathrm{t}}$ will be positive. Specifically, in the empirical application we use the following statistics proposed by Harvey et al. (1998):

$$
H L N=D \frac{\bar{d}}{\sqrt{n^{-1} 2 \pi \widehat{f_{d}(0)}}},
$$

where $D=n^{-1 / 2}\left[n+1-2 h+n^{-1} h(h-1)\right]^{1 / 2}, \bar{d}=n^{-1} \sum_{t=T+1}^{T+n} d_{t}, d_{t}=$ $e_{1 t}\left(e_{1 t}-e_{2 t}\right), \widehat{f_{d}(0)}$ is a consistent estimate of the zero-frequency spectral density of $d_{t}, n$ denotes the out-of-sample forecast observations and $h$ is the number of steps ahead. In order to obtain a consistent estimate of $f_{d}(0)$, we follow the recommendations contained in Diebold and Mariano (1995) and Harvey et al. (1997) and use an unweighted sum of the sample autocovariances up to $h-1$ that is $2 \pi \widehat{f_{d}(0)}=\hat{\gamma}_{0}+2 \sum_{\tau=1}^{h-1} \hat{\gamma}_{\tau}$, with $\hat{\gamma}_{k}$ the lag-k sample autocovariance.

\section{Forecast encompassing and combining meth- ods}

The issue of complementarity between RMSFE and the encompassing test is used to develop a hierarchical procedure for the efficient selection of non-nested forecasts to be combined. The procedure considers out-of-sample forecasts as inputs. The basic idea is to compare all forecasting models with each other using the HLN encompassing test in order to eliminate the encompassed models, and to use several methods to combine the remaining forecasts. The hierarchical procedure is described as follows:

Step 1. Calculate the RMSFE of the out-of-sample forecast for each model using out-of-sample forecasts and realized values. Rank the models according to their past performance based on RMSFE;

Step 2. Select the best forecasting model (i.e. the model with the lowest RMSFE), and using the HLN statistics test sequentially whether the best forecasting model encompasses other models. If the best model encompasses the alternative model at some significance level $\alpha$, delete the alternative model from the list;

Step 3. Repeat step 2 with the second best model. The list of models includes the best model and those which are not encompassed by the best model;

Step 4. Continue with the third best model and so on, until no encompassed model remains in the list; 
Step 5. Obtain the hierarchical forecast combination (HFC) with all the previously selected models using several forecast combining methods;

Final step. Compare for each combining method the RMSFE for the hierarchical forecast combination (RMSFE $\mathrm{HFC}_{\mathrm{C}}$ ) with the one obtained from the single best model $\left(\mathrm{RMSFE}_{\mathrm{BM}}\right)$ and with that obtained from combining all models $\left(\mathrm{RMSFE}_{\mathrm{ALL}}\right)$. When two relative RMSFE indices are computed ( $\frac{\mathrm{RMSFE}_{\mathrm{HFC}}}{\mathrm{RMSFE}_{\mathrm{BM}}}$ and $\left.\frac{\mathrm{RMSFE}_{\mathrm{HFC}}}{\mathrm{RMSFE}_{\mathrm{ALL}}}\right)$, a ratio of less than one denotes that the hierarchical forecast outperforms the competing models.

Several issues should be addressed regarding the empirical application. Firstly, an initial set of 24 out-of-sample forecasts is considered for applying the HLN test. Secondly, several significance levels $\alpha$ of the HLN test are considered (see section 5). Thirdly, a multiple encompassing F-test (Harvey and Newbold, 2000 ) is applied to verify the robustness of our model selecting procedure based on the HLN encompassing test. At each step of the sequence procedure, the F-test confirms whether the best model encompasses all the competitors or not. Finally, several forecast-combinations methods are used. The combining methods take the form of a linear combination of the individual forecasts:

$$
\hat{y}_{c, t+h \mid t}^{h}=w_{0, t}+\sum_{i=1}^{k} w_{i, t} \hat{y}_{i, t+h \mid t}^{h},
$$

where $\hat{y}_{c, t+h \mid t}^{h}$ is a given combination forecast whose weights, $\left\{w_{i, t}\right\}_{i=0}^{k}$, are computed using the individual out-of-sample forecast, $k$ is the number of the models and $h$ is the forecast horizon. As regards the combining forecast method, we consider:

a) the mean, the trimmed mean and the median. With regard to the mean, we set $\mathrm{w}_{0, \mathrm{t}}=0$ and $\mathrm{w}_{\mathrm{i}, \mathrm{t}}=\frac{1}{\mathrm{k}}$ in equation (8); the trimmed mean uses $\mathrm{w}_{0, \mathrm{t}}=0$ and $\mathrm{w}_{\mathrm{i}, \mathrm{t}}=0$ for the individual models that generate the smallest and largest forecasts at time $\mathrm{t}$, while $\mathrm{w}_{\mathrm{i}, \mathrm{t}}=\frac{1}{(\mathrm{k}-2)}$ for the remaining individual models; with respect to the median (case not encompassed by equation (8)), the sample median of the forecasts set $\left\{\hat{y}_{i, t+h \mid t}^{h}\right\}_{i=1}^{k}$ is computed;

b) the unrestricted OLS combining method (see Granger and Ramanathan, 1984). The combining weights are calculated using OLS regression;

c) the WLS combining method proposed by Diebold and Pauly (1987). We apply the "t-lambda" approach which consists of a combining method with weights calculated by WLS estimator. Diebold and Pauly suggest using the weighting matrix $\Psi=\operatorname{diag}\left[\Psi_{t t}\right]=\left[\kappa t^{\gamma}\right]$, where $\kappa, \gamma>0, t=1, \ldots, T$ and $\mathrm{T}$ is the number of observations used in the WLS regression. In our empirical application we use $\gamma=1$ (weights that decrease at a constant rate) and $\gamma=3$ (weights that decrease at an increasing rate);

d) the DMSFE (Discount Mean Square Forecast Errors) combining methods. Following Stock and Watson (2004), the weights in equation (8) depend inversely on the historical forecasting performance of the individual models:

where

$$
w_{i, t}=\frac{\lambda_{i t}^{-1}}{\sum_{j=1}^{n} \lambda_{j t}^{-1}},
$$

$$
\lambda_{i, t}=\sum_{s=T+1}^{T+n} \delta^{T+n-s}\left(y_{s}^{h}-\hat{y}_{i, s \mid s-h}^{h}\right)^{2},
$$


$w_{0, t}=0$, and $\delta$ is a discount factor. When $\delta=1$ there is no discounting; when $\delta<1$, greater importance is attributed to the recent forecast performance of the individual models. In the empirical application, we use $\delta=0.9,1.0$.

\section{Forecasting models}

In this section the seven time series models for forecasting the Italian industrial production $(I P I)$ are described: four single-equation models, a dynamic factor model, a VAR model, and an ARIMA model. The VAR model is the first to be used at ISAE to obtain IPI multi-step forecasts. The main aim is to forecast the industrial production well beyond two-steps ahead (as the official release is available about 45 days after the end of the reference period). As a result, the choice of the variables is restricted to potential predictors of the industrial production characterized by a well defined leading pattern (Bruno and Lupi, 2004). As regards the very short-run horizons, the forecasting performance of the VAR model substantially deteriorates with the persistent moderation of industrial activity. To improve the predictive accuracy in the short-run, especially concerning the estimation of the nowcasts, a number of single-equation models are developed. Some specifications are based on both coincident and quantitative indicators of the industrial production, taken at their latest available updates. One single-equation specification is exclusively based on indicators obtained applying a factor model to ISAE business survey data. As these data are promptly available towards the end of the respective month, this model is aimed at obtaining estimates of industrial production in advance with respect to the models based on hard indicators, which are released about half a week after the end of the month. In addition, once the differences in publication lags are accounted for, the contribution of hard indicators to the forecast is lessened while the contribution of the business surveys becomes of preeminent importance (Banbura and Rünstler, 2007).

The general specification of single-equation multivariate models is:

$$
\Delta_{12} y_{t}=\alpha+\gamma \Delta_{12} y_{t-h}+\sum_{j=h}^{p} \beta_{j} x_{t-j}^{m_{h}}+\delta d_{t}+\varepsilon_{t}^{m_{h}},
$$

where $y_{t}$ is the log-transformed industrial production index, $m$ denotes the models for each forecasting step $(h=1, \ldots, 6), \Delta_{12}=\left(1-L^{12}\right), d_{t}$ denotes the deterministic components (month-on-month trading days variation up to $1 \mathrm{lag}$ ), $x^{m_{h}}$ are not seasonally adjusted regressors and $\varepsilon_{t}$ is the idiosyncratic error term. The regressors are log-transformed and seasonal differenced in order to obtain stationarity. All variables are considered at monthly frequency.

Specifically, the SE model includes the quantity of raw materials transported by rails $(T O N N)$ and the purchasing managers' index $(P M I)$ as regressors. The $P M I$ index is not differenced and rendered unbounded through the following transformation: $(P M I-50) / 100$. The GW model includes the following regressors: the supply of electric energy $(E E)$, the lagged endogenous variable and the $P M I$. In the third model $\mathrm{GW}_{\mathrm{c}}$, the supply of electric energy $(E E)$, $P M I$ (both lagged by 1 period), the variable $\tilde{\mathrm{C}}_{q, t}$ and a set of seasonal dummies (which take value equal to $\tilde{\mathrm{C}}_{q, t}$ in the reference month and zero otherwise) are included. The $\tilde{\mathrm{C}}_{q, t}$ variable is defined as the deviation of $\mathrm{C}_{q, t}$ (the current 
temperature in period $q$ and year $t$ ) from its average level observed in the same month over the latest five years $\left(\mathrm{C}_{q, t-1}, \ldots, \mathrm{C}_{q, t-5}\right)$. The $\tilde{\mathrm{C}}_{q, t}$ variable is considered since some of the electricity components could be significantly affected by temperature patterns (on this point see Bodo and Signorini, 1987; Bodo, Cividini and Signorini, 1991; Marchetti and Parigi, 2000). The Gas model is based on the volume of natural gas required by the industrial sector (Snam) and $P M I$ index.

For each single-equation model, a reduced form is obtained from a general unrestricted model (GUM) which is estimated over the period 1997:1-2005:9 (with the exception of the Gas model) using up to the 12th lag of the independent and dependent variables. The General-to-Specific approach is performed running Pc-Gets and the 'conservative' selection strategy is chosen. It delivers an overall significance level of approximately 1\% (Hendry and Krolzig, 1999; Krolzig and Hendry, 2001). To get forecasts for more than one-step ahead without using any prediction of the selected indicators, each $G U M$ is constructed discarding lower lagged regressors (Rünstler and Sèdillot, 2003).

In addition, two other models based on different functional forms are considered. Following Stock and Watson $(1998,2002)$, a dynamic factor model (Factor) is estimated:

$$
\Delta_{12} y_{t}^{m_{h}}=\beta_{0}+\sum_{i=1}^{4} B_{i} \hat{F}_{i, t-h}+\gamma \Delta_{12} y_{t-h}+\hat{\varepsilon}_{t}^{m_{h}},
$$

where $m$ denotes the models for each step $(h=1, \ldots, 6)$, and $i=1, \ldots, 4$ are the number of estimated factors $\left(\hat{F}_{i t}\right)$. Lagged values of the dependent variables also appear as predictors since the error term can be serially correlated. The factors are extracted from a large data-set of monthly ISAE business surveys regarding the manufacturing sector (current assessments on demand, production and inventories, short-term prospects for orders, production and prices), expressed in terms of net balance. The survey data are found to be stationary, thus matching the condition required for estimation of factor models. The number of factors are computed using the $\mathrm{IC}(3)$ criterion proposed in Bai and Ng (2002) and the estimates of the factors are obtained using the Principal Component method (Stock and Watson, 1998, 2002).

The second model is based on a VAR specification (Bruno and Lupi, 2004) where indicators are re-parameterized in seasonal differences, since this proves useful in order to obtain quasi-orthogonal regressors. Unrestricted starting model takes the form:

$$
\Delta_{12} y_{t}=\alpha \Delta_{12} y_{t-1}+\sum_{j=1}^{13} \beta_{j} \Delta \Delta_{12} y_{t-j}+\phi d_{t}+\varepsilon_{t},
$$

where $y_{t}=\left(I P I_{t}, T O N N_{t}, P P_{t}\right), \Delta=(1-L), \Delta_{12}=\left(1-L^{12}\right), P P$ denotes monthly ISAE production expectations which are rendered unbounded through the transformation $-\log (200 /(P P+100)-1)$ and $d_{t}$ represents the deterministic components (for the specification of the deterministic components see Bruno and Lupi, 2004). Finally, we consider an ARIMA time series model as a benchmark model which involves double differencing, both at regular and seasonal frequencies. According to the Schwarz information criterion for lag length selection, the final specification consists of an $\operatorname{ARMA}(2,3)$ polynomial for the regular part, $\mathrm{MA}(1)_{12}$ for the seasonal frequencies.

The indicators relative to all of the above models are plotted in Figure 1 which 
shows the log-transformed $I P I$, the energy indicators (EE and Snam) and the raw materials $(T O N N)$ in seasonal differences, the unbounded $P P$ and $P M I$.

\section{Empirical results}

All models presented in section 4 are estimated over a common sample 1997:72005:9 (with the exception of the Gas model whose sample begins in 2002:1). In order to evaluate in-sample correct specification the standard diagnostics are performed (the results are available upon request from the authors). The forecasting exercise is carried out using both recursive and rolling schemes. The latter is generally used when there are concerns about turning points and biases from the use of older information. The rolling scheme is used for a sensitivity analysis with respect to the results of the combination obtained through the hierarchical procedure. The dimension of the rolling window varies with each model to account for the different time span over which the indicators are available (starting in 1979 for TONN, in 1991 for IPI and PP, in 1997 for PMI, and in 2001 for Snam).

In Table 1 the RMSFE of the out-sample forecasts for each model is reported. On the basis of these results, the models are ranked from the best to the worst for each forecast horizon (see Table 2). Different results in terms of the ranked models are found for recursive and rolling estimations respectively. With regards to the first-step ahead, the SE model is first ranked in both estimation frameworks, but its forecasting accuracy worsens in the successive steps ahead. When the recursive scheme is considered, the $\mathrm{GW}_{\mathrm{c}}$ model shows higher rankings at several prediction steps and has a slightly better performance than the rolling estimates for $h=1,2$. When six-steps ahead are considered, the VAR model is characterized by significantly higher performances and outperforms all the other models, as is generally expected. Its predictive ability slightly improves in the rolling schemes, due to the process of discarding the more dated observations in presence of the long lag structure of model equations.

On the basis of the rank classification, the HLN test is applied to eliminate models that are encompassed by others (see Tables 3-4). Given the number of steps ahead and the estimation scheme, the number of models selected for combination depends on the significance level. The lower the significance level $\alpha$, the stronger the selection becomes between competing models. As $\alpha$ rises, a larger number of forecasts are selected for combination. As regards the firststep ahead, at the significance level of $25 \%$ four models are selected in the both recursive ( $\mathrm{SE}, \mathrm{GW}, \mathrm{GW}_{\mathrm{c}}, \mathrm{Gas}$ ) and rolling ( $\mathrm{SE}, \mathrm{VAR}, \mathrm{Gas}, \mathrm{GW}_{\mathrm{c}}$ ) schemes. At lower value of $\alpha$, the selected models are reduced to three (the fourth model in each scheme is ruled out respectively) and at significance level of $1 \%$, only the SE model is selected in both estimation frameworks.

In the recursive scheme, the selected models are $\mathrm{GW}_{\mathrm{c}}$ and $\mathrm{SE}$ for $h=2$ irrespective of the significance levels; $\mathrm{GW}_{\mathrm{c}}$ and Gas for $h=3$ (VAR is only chosen when $\alpha=0.25$ ). As regards the rolling estimates, four models enter the combination for $h=2$ and $\alpha \in[0.05,0.25]$ (GW, $\mathrm{GW}_{\mathrm{c}}$, Gas, Factor). The models based on the electricity indicator are the only ones used for the combination when $h=3$ and the GW model is the only selected when $\alpha \leq 0.15$. For the six-steps ahead, the VAR model outperforms all the other models.

The multiple encompassing F-test would seem to confirm the HLN test findings 
(similar results are found using the multivariate analogue Diebold-Mariano test, $M S^{*}$, also proposed by Harvey and Newbold (2000). They are available upon request from the authors). The selection model results are reported in Table 5. The F-test is applied to each best model against all the competing models at all steps of the hierarchical procedure. For each significance level, the rejection of the null hypothesis indicates that at least some of the rival models are not encompassed by the best model. As regards the one-step horizon for the recursive scheme, the F-test supports the HLN test results at each step of the procedure. Thus, the multiple encompassing test assesses the robustness of our hierarchical algorithm in selecting models that are not encompassed. Similar results are found for the rolling scheme. With respect to the second-step ahead for the recursive scheme, the F-test confirms the results based on the HLN test. The only difference is found in the first step of the hierarchical procedure in which the F-test rejects the null hypothesis at significance level of $5 \%$ (instead of $1 \%$ as is observed in the HLN test). In the rolling scheme, for $h=1,2$, the F-test results show higher probability than that one in the HLN test. Thus there is a greater tendency to accept the null hypothesis of encompassing. For $h>2$, multiple encompassing F-test confirms the HLN test results.

As a general result from the empirical exercise, the recursive scheme generally provides better findings in terms of forecasting accuracy. In this framework, the superiority of the hierarchical combination turns out to be substantially better when longer forecast horizons are concerned $(h>1)$. For the first-step ahead, the forecast accuracy of the combination algorithm results only slightly better than the one obtained in the rolling scheme.

When model selection takes place, the hierarchical combination is able to outperform both the single best model and the combination of the overall models in terms of RMSFE. In order to assess the robustness of the algorithm procedure, we evaluate the relative RMSFE, computed as a ratio between the RMSFE of the hierarchical forecast combination (HFC) and the RMSFE from both the best single model $(\mathrm{BM})$ and the combination of overall models $(\mathrm{ALL})\left(\mathrm{RMSFE}_{\mathrm{HFC} / \mathrm{BM}}\right.$ and $\mathrm{RMSFE}_{\mathrm{HFC} / \mathrm{ALL}}$ respectively; see Table 6). Results for the six-steps ahead are not reported as the first ranked model systematically encompasses all the others regardless of the significance levels. The RMSFE indices are significantly less than one in many cases at $5 \%$. These findings confirm the goodness of the hierarchical procedure.

Regardless of the combination methods and of the number of steps ahead, the best results in terms of relative RMSFE are obtained for higher significance levels, hence allowing for the averaging of a large number of models. At the low significance levels, very few forecasts are considered for combination and the overall forecast benefits less from the advantages of combining. The upper significance level is set at $\alpha=0.25$, since no significant improvement in terms of forecast accuracy is found using the hierarchical combination for higher significance values. Similar results are also found in Kisinbay (2007).

The performance of the several combination methods can be ranked in terms of relative RMSFE. In both schemes, the basic linear pooling methodologies (mean, median and trimmed mean) perform remarkably better than other combination methods (with the only exception of the OLS method in the case of rolling scheme for the $\mathrm{RMSFE}_{\mathrm{HFC} / \mathrm{BM}}$ and $\mathrm{h}=2$ ). These results are consistent with the prevailing international literature and with most of the Italian empirical evidence. With respect to the Italian forecasting research, Bodo and 
Signorini (1987) and Bodo, Cividini and Signorini (1991) find that the combination forecasts are better than any single model in terms of the RMSFE and that the simple average methods for combination provide better results. In contrast to this evidence, Marchetti and Parigi (2000) find that the combination of forecasts is not fully satisfactory as yields only marginal improvements when several methods of combining forecasts are used.

The relative RMSFE is also less than one in the case of discounted combination method (DMSFE) in which the weights are estimated so as to be affected by most recent past model performance (Newbold and Harvey, 2002). The worst results are obtained using the WLS method. Recent literature has stressed the poorer performance of this method for combination (Newbold, Zumwalt and Kannan, 1987).

\section{Conclusions}

In this paper a hierarchical procedure to increase the efficiency of forecasting combining methods is provided. The procedure considers out-of-sample forecasts as inputs. Ericsson (1992) shows that the forecast encompassing of a given model versus the other non-nested models is a sufficient condition to minimize RMSFE. This result is employed in our hierarchical procedure. The basic idea is to compare all forecasting models with each other using the Harvey et al. (1998) encompassing test in one direction in order to eliminate those models which are encompassed by others, and subsequently to use several forecast combining methods to combine the remaining forecasts. Thus, the hierarchical procedure aims to unit model selection and model averaging methods, using larger weights for forecasts that provide information which is not contained in most of the remaining models and discounting the predictions that are encompassed by other forecasts. The robustness of the procedure is then investigated in terms of the relative RMSFE using ISAE (Institute for Studies and Economic Analyses) short-term forecasting models for monthly industrial production in Italy. Results confirm the goodness of the hierarchical procedure.

\section{References}

Bai, J. \& Ng, S. (2002). Determining the Number of Factors in Approximate Factor Models. Econometrica, 70, 191-221.

Banbura, M. \& Rünstler, G. (2007). A look into the factor model black box publication lags and the role of hard and soft data in forecasting GDP, Working Paper Series 751, European Central Bank.

Bodo, G., Cividini, A. and Signorini, L. F. (1991). Forecasting the Italian industrial production index in real time, Journal of Forecasting, 10, 285-99.

Bodo, G. and Signorini, L. F. (1987). Short-term forecasting of the industrial production index, International Journal of Forecasting, 3, 245-9.

Bruno, G. \& Lupi, C. (2004). Forecasting industrial production and the early detection of turning points. Empirical Economics, 29, 647-671.

Diebold, F.X. \& Mariano, R. (1995). Comparing Predictive Accuracy. Journal of Business and Economic Statistics, 13, 253-263. 
Diebold, F.X. \& Pauly, P. (1987). Structural Change and the Combination of Forecasts. Journal of Forecasting, 6, 21-40.

Ericsson, N. R. (1992). Parameter Constancy, Mean Square Forecast Errors, and Measuring Forecast Performance: An Exposition, Extensions, and Illustration. Journal of Policy Modelling, 4, 465-495.

Granger, C. W. J. \& Ramanathan, R. (1984). Improved Methods of Combining Forecasts. Journal of Forecasting, 3, 197-204.

Harvey, D., Leybourne, S. \& Newbold, P. (1997). Testing the equality of prediction mean squared errors. International Journal of Forecasting, 13, 281-291. Harvey, D. I., Leybourne, S. \& Newbold, P. (1998). Tests for forecast encompassing. Journal of Business and Economic Statistics, 16, 254-259.

Harvey, D. \& Newbold, P. (2000). Tests for multiple forecast encompassing, Journal of Applied Econometrics, 15, 471-482.

Hendry, D. F \& Clements, M. P. (2004). Pooling of Forecasts, Econometrics Journal, volume 7, 131.

Hendry, D. F. \& Krolzig, H.M. (1999). Improving on Data mining reconsidered by K.D. Hoover and S.J. Perez. Econometrics Journal, 2, 202-219.

Kisinbay, T. (2007) The Use of Encompassing Tests for Forecast Combinations. Working paper, International Monetary Found, 264, 1-21.

Krolzig, H. M. \& Hendry, D. F. (2001). Computer automation of general-tospecific model selection procedures. Journal of Economic Dynamics and Control, 25, 831-866.

Marchetti, D.J. and Parigi, G. (2000). Energy consumption, survey data and the prediction of industrial production in Italy: a comparison and combination of different models, Journal of Forecasting, 19, 419-440.

Newbold, P. \& Harvey, I. H. (2002) Forecast Combination and Encompassing. In: M.P. Clements \& D.F. Hendry A Companion to Economic Forecasting. Blackwell Publishers, pp. 268-283.

Newbold, P., Zumwalt, J. K. \& Kannan, S. (1987). Combining forecasts to improve earnings per share prediction: and examination of electric utilities. International Journal of Forecasting, 3, 229-238.

Rünstler G. \& Sèdillot, F. (2003). Short-term Estimates of Euro Area Real Gdp by Means of Monthly Data, ECB Working Paper, n. 276.

Stock, J. H. \& Watson, M. W. (1998). Diffusion indexes. Working Paper 6702, NBER, 1-65.

Stock, J. H. \& Watson, M. W. (2002). Macroeconomic forecasting using diffusion indices. Journal of Business and Economic Statistics, 20, 147-162.

Stock J. H. \& Watson, M. W. (2004). Combination forecasts of output growth in a seven-country data set. Journal of Forecasting, 23, 405-430. 

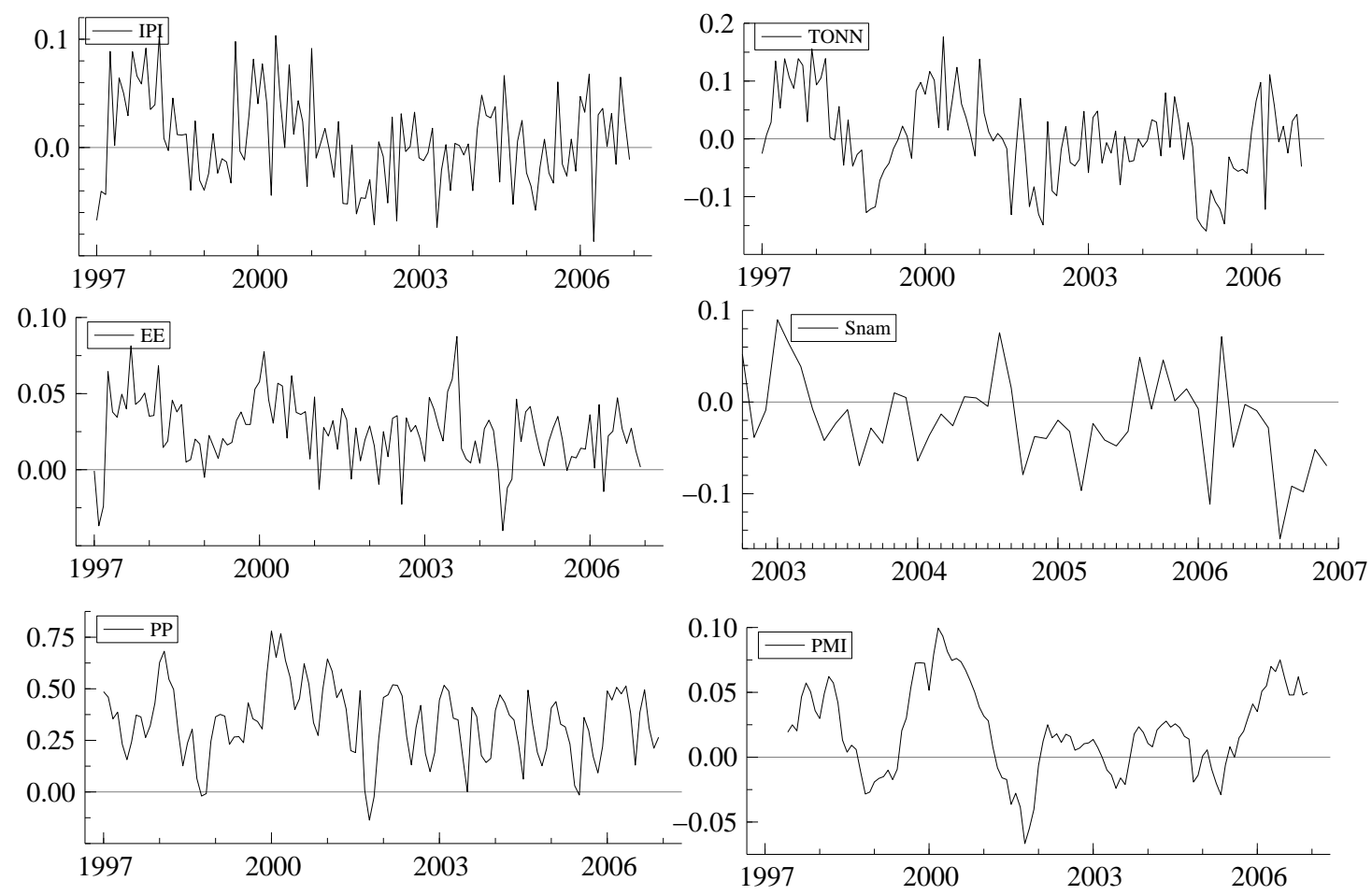

Figure 1: Indicators for forecasting models. 
Table 1: Forecast errors measures. Recursive and Rolling estimation

\begin{tabular}{l|c|c|c|c}
\hline Models (recursive) & RMSFE(1) & RMSFE(2) & RMSFE(3) & RMSFE(6) \\
\hline GW & 0.0192 & 0.0211 & 0.0388 & 0.0423 \\
Gas & 0.0205 & 0.0203 & 0.0214 & 0.0270 \\
$\mathrm{GW}_{\mathrm{c}}$ & 0.0201 & 0.0168 & 0.0202 & 0.0222 \\
$\mathrm{SE}$ & 0.0180 & 0.0182 & 0.0399 & 0.0379 \\
$\mathrm{VAR}$ & 0.0236 & 0.0240 & 0.0243 & 0.0206 \\
ARIMA & 0.0297 & 0.0265 & 0.0391 & 0.0413 \\
Factor & 0.0279 & 0.0210 & 0.0372 & 0.0368 \\
\hline Models (rolling) & $\mathrm{RMSFE}(1)$ & $\mathrm{RMSFE}(2)$ & $\mathrm{RMSFE}(3)$ & $\mathrm{RMSFE}(6)$ \\
\hline GW & 0.0375 & 0.0194 & 0.0202 & 0.0248 \\
Gas & 0.0342 & 0.0207 & 0.0215 & 0.0254 \\
GW & 0.0344 & 0.0206 & 0.0207 & 0.0230 \\
$\mathrm{SE}$ & 0.0178 & 0.0422 & 0.0412 & 0.0352 \\
VAR & 0.0314 & 0.0315 & 0.0303 & 0.0213 \\
ARIMA & 0.0367 & 0.0353 & 0.0353 & 0.0354 \\
Factor & 0.0388 & 0.0272 & 0.0400 & 0.0367 \\
\hline
\end{tabular}

Notes: numbers in parentheses are the steps-ahead forecast.

Table 2: Rank Classification. Recursive and Rolling estimation

\begin{tabular}{l|c|c|c|c|c|c|c|c}
\hline & \multicolumn{5}{|c|}{ Recursive } & \multicolumn{4}{c}{ Rolling } \\
\hline rank & $\mathrm{h}=1$ & $\mathrm{~h}=2$ & $\mathrm{~h}=3$ & $\mathrm{~h}=6$ & $\mathrm{~h}=1$ & $\mathrm{~h}=2$ & $\mathrm{~h}=3$ & $\mathrm{~h}=6$ \\
\hline 1 & $\mathrm{SE}$ & $\mathrm{GW}_{\mathrm{C}}$ & $\mathrm{GW}_{\mathrm{c}}$ & $\mathrm{VAR}$ & $\mathrm{SE}$ & $\mathrm{GW}$ & $\mathrm{GW}$ & $\mathrm{VAR}$ \\
2 & $\mathrm{GW}$ & $\mathrm{SE}$ & $\mathrm{Gas}$ & $\mathrm{GW}_{\mathrm{C}}$ & $\mathrm{VAR}$ & $\mathrm{GW}_{\mathrm{C}}$ & $\mathrm{GW}_{\mathrm{c}}$ & $\mathrm{GW}_{\mathrm{C}}$ \\
3 & $\mathrm{GW}_{\mathrm{C}}$ & $\mathrm{Gas}$ & $\mathrm{VAR}$ & $\mathrm{Gas}$ & $\mathrm{Gas}$ & $\mathrm{Gas}$ & $\mathrm{Gas}$ & $\mathrm{GW}$ \\
4 & $\mathrm{Gas}$ & Factor & Factor & Factor & $\mathrm{GW}_{\mathrm{C}}$ & Factor & VAR & $\mathrm{Gas}$ \\
5 & VAR & $\mathrm{GW}$ & $\mathrm{GW}$ & $\mathrm{SE}$ & ARIMA & VAR & ARIMA & SE \\
6 & Factor & VAR & SE & ARIMA & GW & ARIMA & Factor & ARIMA \\
7 & ARIMA & ARIMA & ARIMA & GW & Factor & SE & SE & Factor \\
\hline
\end{tabular}


Table 3: Encompassing (HLN) test results. Recursive estimation.

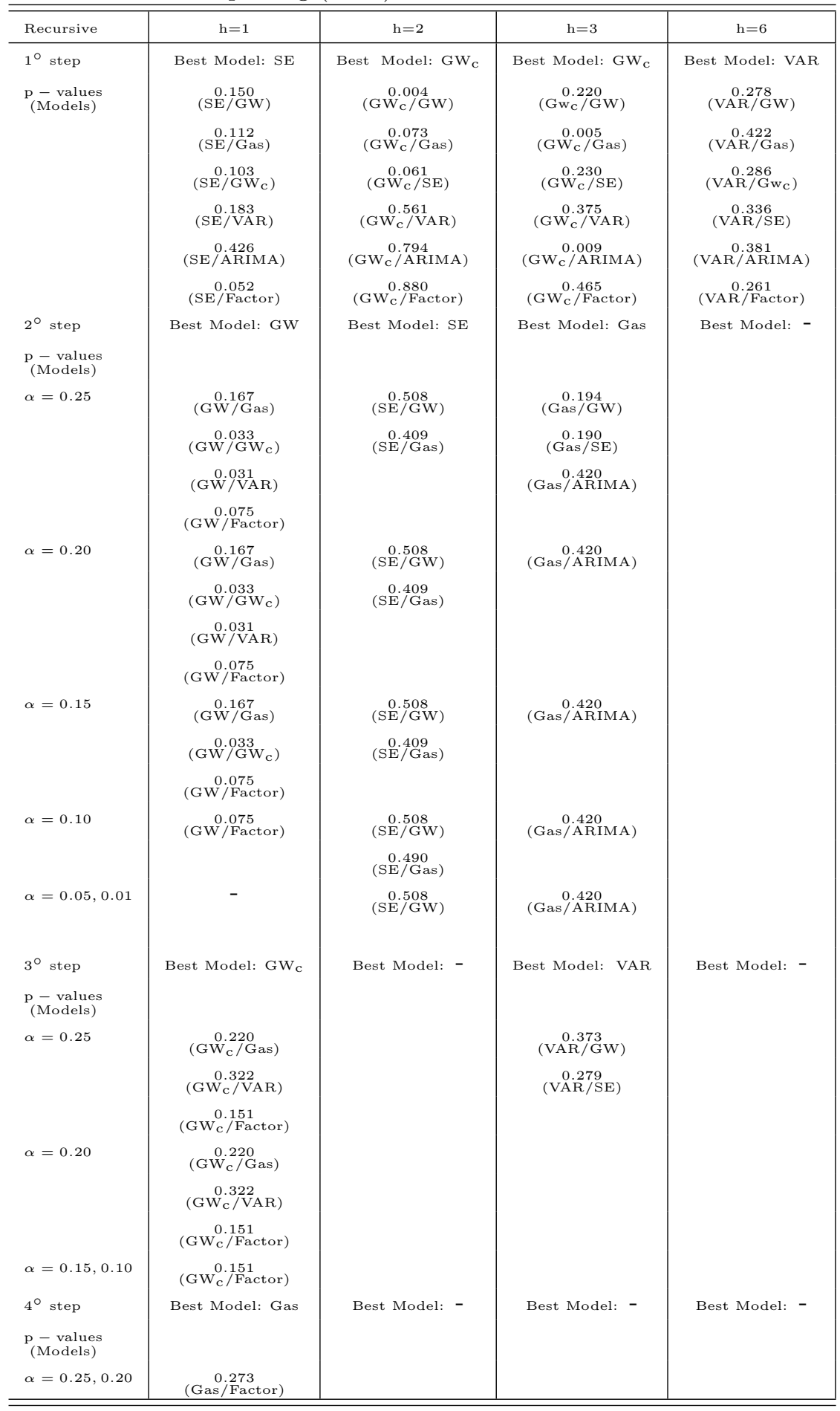


Table 4: Encompassing (HLN) test results. Rolling estimation.

\begin{tabular}{|c|c|c|c|c|}
\hline Rolling & $\mathrm{h}=1$ & $\mathrm{~h}=2$ & $\mathrm{~h}=3$ & $\mathrm{~h}=6$ \\
\hline $1^{\circ}$ step & Best Model: SE & Best Model: GW & Best Model: GW & Best Model: VAR \\
\hline \multirow[t]{6}{*}{$\begin{array}{l}\mathrm{p} \text { (Models) } \\
\text { (Malues }\end{array}$} & $(\mathrm{SE} / \mathrm{GW})$ & $\begin{array}{c}0.874 \\
(\mathrm{GW} / \mathrm{Gas})\end{array}$ & $\begin{array}{c}0.657 \\
(\mathrm{GW} / \mathrm{Gas})\end{array}$ & $\begin{array}{c}0.269 \\
(\mathrm{VAR} / \mathrm{GW})\end{array}$ \\
\hline & $\begin{array}{l}0.070 \\
\text { (SE/Gas) }\end{array}$ & ( $\stackrel{0.279}{\text { GW/ } / \mathrm{GW}_{\mathrm{C}}}$ ) & $\begin{array}{c}0.290 \\
\left(\mathrm{GW} / \mathrm{GW}_{\mathrm{C}}\right)\end{array}$ & $\begin{array}{c}0.546 \\
\text { (VAR/Gas) }\end{array}$ \\
\hline & $\begin{array}{l}0.243 \\
\left(\mathrm{SE} / \mathrm{GW}_{\mathrm{C}}\right)\end{array}$ & $\begin{array}{c}0.256 \\
(\mathrm{GW} / \mathrm{SE})\end{array}$ & $\begin{array}{c}0.274 \\
(\mathrm{GW} / \mathrm{SE})\end{array}$ & $\begin{array}{c}0.256 \\
\left(\mathrm{VAR} / \mathrm{Gw}_{\mathrm{C}}\right)\end{array}$ \\
\hline & $\begin{array}{l}0.065 \\
\text { (SE/VAR) }\end{array}$ & (GW/V306 $)$ & $\begin{array}{l}0.331 \\
\text { (GW/VAR) }\end{array}$ & $\begin{array}{l}0.597 \\
\text { (VAR/SE) }\end{array}$ \\
\hline & $\begin{array}{c}0.595 \\
\text { (SE/ARIMA) }\end{array}$ & $\begin{array}{c}0.502 \\
\text { (GW/ARIMA) }\end{array}$ & $\begin{array}{c}0.214 \\
\text { (GW/ARIMA) }\end{array}$ & $\begin{array}{c}0.304 \\
\text { (VAR/ARIMA) }\end{array}$ \\
\hline & $\begin{array}{c}0.206 \\
\text { (SE/Factor) }\end{array}$ & $\begin{array}{c}0.019 \\
\text { (GW/Factor) }\end{array}$ & $\begin{array}{c}0.197 \\
\text { (GW/Factor) }\end{array}$ & $\begin{array}{c}0.359 \\
\text { (VAR/Factor) }\end{array}$ \\
\hline $2^{\circ}$ step & Best Model: VAR & Best Model: $\mathrm{GW}_{\mathrm{C}}$ & Best Mode: $\mathrm{GW}_{\mathrm{C}}$ & Best Model: - \\
\hline $\begin{array}{l}\mathrm{p} \text { - values } \\
\text { (Models) }\end{array}$ & & & & \\
\hline \multirow[t]{4}{*}{$\alpha=0.25$} & $\begin{array}{c}0.086 \\
\text { (VAR/GW) }\end{array}$ & $\begin{array}{c}0.007 \\
\left(\mathrm{GW}_{\mathrm{c}} / \text { Factor }\right)\end{array}$ & $\left(\mathrm{GW}_{\mathrm{c}}^{0.707}\right.$ /ARIMA) & \\
\hline & $\begin{array}{c}0.049 \\
\text { (VAR/Gas) }\end{array}$ & & $\begin{array}{c}0.467 \\
\text { (GW } / \text { Factor) }\end{array}$ & \\
\hline & $\left(\begin{array}{l}0.085 \\
\left(\mathrm{VAR} / \mathrm{GW}_{\mathrm{C}}\right)\end{array}\right.$ & & & \\
\hline & $\begin{array}{c}0.029 \\
\text { (VAR/Factor) }\end{array}$ & & & \\
\hline \multirow[t]{2}{*}{$\alpha=0.20$} & $\begin{array}{c}0.086 \\
(\mathrm{VAR} / \mathrm{GW})\end{array}$ & $\begin{array}{c}0.007 \\
\left(\mathrm{GW}_{\mathrm{C}} / \text { Factor }\right)\end{array}$ & $\begin{array}{c}0.467 \\
\left(\mathrm{GW}_{\mathrm{C}} / \text { Factor }\right)\end{array}$ & \\
\hline & $\begin{array}{c}0.049 \\
\text { (VAR/Gas) }\end{array}$ & & & \\
\hline$\alpha=0.15,0.10$ & $\begin{array}{c}0.049 \\
\text { (VAR/Gas) }\end{array}$ & $\begin{array}{c}0.007 \\
\left(\mathrm{GW}_{\mathrm{c}}^{0} / \text { Factor }\right)\end{array}$ & & \\
\hline$\alpha=0.05$ & - & $\begin{array}{c}0.007 \\
\left(\mathrm{GW}_{\mathrm{c}} / \text { Factor }\right)\end{array}$ & & \\
\hline$\alpha=0.01$ & - & - & & \\
\hline $3^{\circ}$ step & Best Model: Gas & Best Model: Gas & Best Model: - & Best Model: - \\
\hline \multicolumn{5}{|l|}{$\mathrm{p}$ (Models) } \\
\hline \multirow[t]{3}{*}{$\alpha=0.25$} & $\begin{array}{c}0.776 \\
(\mathrm{Gas} / \mathrm{GW})\end{array}$ & $\begin{array}{c}0.144 \\
\text { (Gas/Factor) }\end{array}$ & & \\
\hline & $\begin{array}{c}0.243 \\
\left(\mathrm{Gas} / \mathrm{GW}_{\mathrm{C}}\right)\end{array}$ & & & \\
\hline & $\begin{array}{c}0.075 \\
\text { (Gas/Factor) }\end{array}$ & & & \\
\hline$\alpha=0.20,0.15,0.10$ & $\begin{array}{c}0.776 \\
(\mathrm{Gas} / \mathrm{GW})\end{array}$ & $\begin{array}{c}0.144 \\
\text { (Gas/Factor) }\end{array}$ & & \\
\hline$\alpha=0.05$ & & $\begin{array}{c}0.144 \\
\text { (Gas/Factor) }\end{array}$ & & \\
\hline $4^{\circ}$ step & Best Model: $\mathrm{GW}_{\mathrm{C}}$ & Best Model - & Best Model - & Best Model - \\
\hline $\begin{array}{l}\mathrm{p}-\text { values } \\
\text { (Models) }\end{array}$ & & & & \\
\hline$\alpha=0.25$ & $\begin{array}{c}0.600 \\
\left(\mathrm{GW}_{\mathrm{C}} / \text { Factor }\right)\end{array}$ & & & \\
\hline
\end{tabular}


Table 5: Multiple encompassing test results. Recursive and Rolling estimation.

\begin{tabular}{|c|c|c|c|c|}
\hline Recursive & $\mathrm{h}=1$ & $\mathrm{~h}=2$ & $\mathrm{~h}=3$ & $\mathrm{~h}=6$ \\
\hline $\begin{array}{l}1^{\circ} \text { step } \\
\text { F-test } \\
(\mathrm{p}-\text { values })\end{array}$ & $\begin{array}{c}\text { Best Model: SE } \\
3.16 \\
(0.069)\end{array}$ & $\begin{array}{c}\text { Best Model: } \mathrm{GW}_{\mathrm{C}} \\
3.96 \\
(0.041)\end{array}$ & $\begin{array}{c}\text { Best Model: } \mathrm{GW}_{\mathrm{C}} \\
\\
(0.89 \\
(0.018)\end{array}$ & $\begin{array}{c}\text { Best Model: VAR } \\
0.94 \\
(0.380)\end{array}$ \\
\hline $\begin{array}{l}2^{\circ} \text { step } \\
\begin{array}{l}\mathrm{F}-\text { test } \\
(\mathrm{p}-\text { values })\end{array}\end{array}$ & $\begin{array}{c}\text { Best Model: GW } \\
\\
4.12 \\
(0.034)\end{array}$ & $\begin{array}{c}\text { Best Model: SE } \\
0.63 \\
(0.543)\end{array}$ & $\begin{array}{c}\text { Best Model: Gas } \\
\\
2.65 \\
(0.183)\end{array}$ & Best Model: - \\
\hline $\begin{array}{l}3^{\circ} \text { step } \\
\text { F-test } \\
(\mathrm{p}-\text { values })\end{array}$ & $\begin{array}{c}\text { Best Model: } \mathrm{GW}_{\mathrm{C}} \\
2.12 \\
(0.182)\end{array}$ & Best Model: - & $\begin{array}{c}\text { Best Model: VAR } \\
0.87 \\
(0.452)\end{array}$ & Best Model: - \\
\hline $\begin{array}{l}4^{\circ} \text { step } \\
\begin{array}{c}\mathrm{F}-\text { test } \\
\text { (p-values) }\end{array} \\
\end{array}$ & $\begin{array}{c}\text { Best Model: Gas } \\
\\
1.45 \\
(0.281) \\
\end{array}$ & Best Model: - & Best Model: - & Best Model: - \\
\hline Rolling & $\mathrm{h}=1$ & $\mathrm{~h}=2$ & $\mathrm{~h}=3$ & $\mathrm{~h}=6$ \\
\hline $\begin{array}{l}1^{\circ} \text { step } \\
\begin{array}{l}\mathrm{F}-\text { test } \\
(\mathrm{p}-\text { values })\end{array}\end{array}$ & $\begin{array}{c}\text { Best Model: SE } \\
1.96 \\
(0.064)\end{array}$ & $\begin{array}{c}\text { Best Model: GW } \\
\\
3.87 \\
(0.044)\end{array}$ & $\begin{array}{c}\text { Best Model: GW } \\
1.85 \\
(0.210)\end{array}$ & $\begin{array}{c}\text { Best Model: VAR } \\
0.76 \\
(0.517)\end{array}$ \\
\hline $\begin{array}{l}2^{\circ} \text { step } \\
\text { F-test } \\
(\mathrm{p}-\text { values })\end{array}$ & $\begin{array}{c}\text { Best Model: VAR } \\
\begin{array}{c}2.80 \\
(0.092)\end{array}\end{array}$ & $\begin{array}{c}\text { Best Model: } \mathrm{GW}_{\mathrm{C}} \\
2.14 \\
(0.180)\end{array}$ & $\begin{array}{c}\text { Best Model: } \mathrm{GW}_{\mathrm{C}} \\
0.35 \\
(0.643)\end{array}$ & Best Model: - \\
\hline $\begin{array}{l}3^{\circ} \text { step } \\
\text { F-test } \\
(\mathrm{p}-\text { values })\end{array}$ & $\begin{array}{c}\text { Best Model: Gas } \\
\\
\begin{array}{c}1.80 \\
(0.99)\end{array}\end{array}$ & $\begin{array}{c}\text { Best Model: Gas } \\
\\
1.31 \\
(0.298)\end{array}$ & Best Model: - & Best Model: - \\
\hline $\begin{array}{l}4^{\circ} \text { step } \\
\begin{array}{l}\mathrm{F}-\text { test } \\
(\mathrm{p}-\text { values })\end{array}\end{array}$ & $\begin{array}{c}\text { Best Model: } \mathrm{GW}_{\mathrm{C}} \\
0.26 \\
(0.763) \\
\end{array}$ & Best Model: - & Best Model: - & Best Model: - \\
\hline
\end{tabular}


Table 6: Relative RMSFE results. Recursive and Rolling estimation.

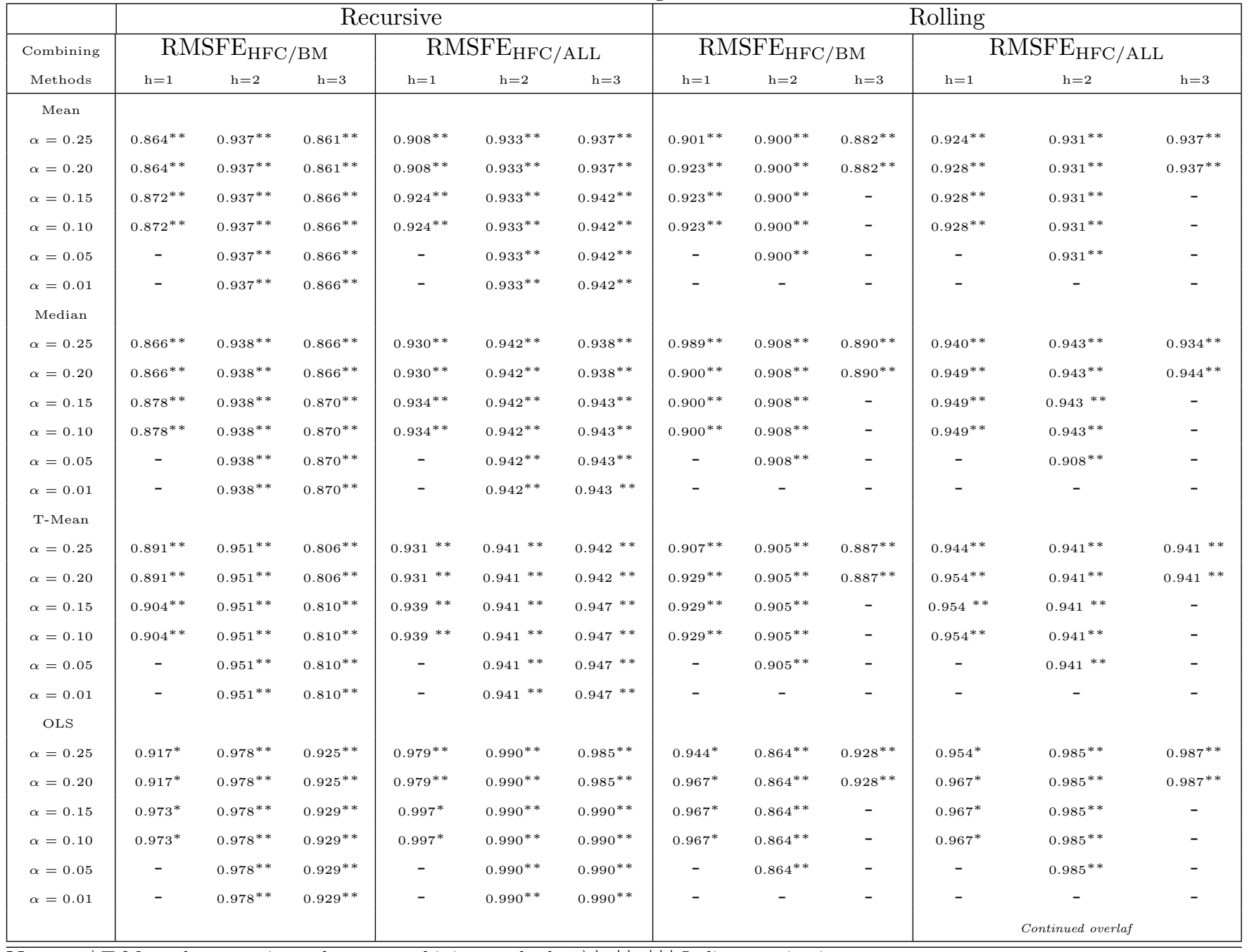

Notes: i) T-Mean denotes trimmed mean combining method; ii)*, **, ${ }^{* * *}$ Indicates rejection of the null hypothesis of equal forecasting accuracy at 10\%, $5 \%, 1 \%$. 
Table 6: Continued.

\begin{tabular}{|c|c|c|c|c|c|c|c|c|c|c|c|c|}
\hline \multirow{3}{*}{$\begin{array}{c}\text { Combining } \\
\text { Methods }\end{array}$} & \multicolumn{6}{|c|}{ Recursive } & \multicolumn{6}{|c|}{ Rolling } \\
\hline & \multicolumn{3}{|c|}{$\mathrm{RMSFE}_{\mathrm{HFC} / \mathrm{BM}}$} & \multicolumn{3}{|c|}{$\mathrm{RMSFE}_{\mathrm{HFC} / \mathrm{ALL}}$} & \multicolumn{3}{|c|}{$\mathrm{RMSFE}_{\mathrm{HFC} / \mathrm{BM}}$} & \multicolumn{3}{|c|}{$\mathrm{RMSFE}_{\mathrm{HFC} / \mathrm{ALL}}$} \\
\hline & $\mathrm{h}=1$ & $\mathrm{~h}=2$ & $\mathrm{~h}=3$ & $\mathrm{~h}=1$ & $\mathrm{~h}=2$ & $\mathrm{~h}=3$ & $\mathrm{~h}=1$ & $\mathrm{~h}=2$ & $\mathrm{~h}=3$ & $\mathrm{~h}=1$ & $\mathrm{~h}=2$ & $\mathrm{~h}=3$ \\
\hline WLS $(\gamma=1)$ & & & & & & & & & & & & \\
\hline$\alpha=0.25$ & $0.937^{* *}$ & $0.999^{* *}$ & $0.864^{* *}$ & $0.981^{* *}$ & $0.998^{*}$ & $0.971^{*}$ & 0.971 & $0.971^{*}$ & $0.951 *$ & 1.003 & $0.996^{*}$ & $0.998^{*}$ \\
\hline$\alpha=0.20$ & $0.937^{* *}$ & $0.999^{* *}$ & $0.864^{* *}$ & $0.981^{* *}$ & $0.998^{* *}$ & $0.971^{*}$ & 0.988 & $0.971^{*}$ & $0.951^{*}$ & 1.002 & $0.996^{*}$ & $0.998^{*}$ \\
\hline$\alpha=0.15$ & $0.938^{* *}$ & $0.999^{* *}$ & $0.869^{* *}$ & $0.986^{* *}$ & $0.998^{* *}$ & $0.976^{*}$ & 0.988 & $0.971^{*}$ & - & 1.002 & $0.996^{*}$ & - \\
\hline$\alpha=0.10$ & $0.938^{* *}$ & $0.999^{* *}$ & $0.869^{* *}$ & $0.986^{* *}$ & $0.998^{* *}$ & $0.976^{*}$ & 0.988 & $0.971^{*}$ & - & 1.002 & $0.996^{*}$ & - \\
\hline$\alpha=0.05$ & - & $0.999^{* *}$ & $0.869 * *$ & - & $0.998^{* *}$ & $0.976^{*}$ & - & $0.971^{*}$ & - & - & $0.996^{*}$ & - \\
\hline $\begin{array}{c}\alpha=0.01 \\
\text { WLS }(\gamma=3)\end{array}$ & - & $0.999 * *$ & $0.869^{* *}$ & - & $0.998^{* *}$ & $0.976^{*}$ & - & - & - & - & - & - \\
\hline$\alpha=0.25$ & $0.936^{*}$ & $0.998^{* *}$ & 0.945 & 0.982 & $0.993^{*}$ & 1.035 & $0.929^{*}$ & 0.967 & 0.941 & 1.007 & 1.017 & 1.010 \\
\hline$\alpha=0.20$ & $0.936^{*}$ & $0.998^{* *}$ & 0.945 & 0.982 & $0.993^{*}$ & 1.035 & 0.983 & 0.967 & 0.941 & 1.013 & 1.017 & 1.010 \\
\hline$\alpha=0.15$ & 0.942 & $0.998^{* *}$ & 0.950 & 0.995 & $0.993^{*}$ & 1.041 & 0.983 & 0.967 & - & 1.013 & 1.017 & - \\
\hline$\alpha=0.10$ & 0.942 & $0.998^{* *}$ & 0.950 & 0.995 & $0.993^{*}$ & 1.041 & 0.983 & 0.967 & - & 1.013 & 1.017 & - \\
\hline$\alpha=0.05$ & - & $0.998^{* *}$ & 0.950 & - & $0.993^{*}$ & 1.041 & - & 0.967 & - & - & 1.017 & - \\
\hline $\begin{array}{c}\alpha=0.01 \\
\operatorname{DMSFE}(\delta=1)\end{array}$ & - & $0.998^{* *}$ & 0.950 & - & $0.993^{*}$ & 1.041 & - & - & - & - & - & - \\
\hline$\alpha=0.25$ & $0.883^{* *}$ & $0.942^{* *}$ & $0.862^{* *}$ & $0.948^{* *}$ & $0.959^{* *}$ & $0.960 * *$ & $0.919^{* *}$ & $0.944 * *$ & $0.923 * *$ & $0.963^{* *}$ & $0.953^{* *}$ & $0.958 * *$ \\
\hline$\alpha=0.20$ & $0.883^{* *}$ & $0.942 * *$ & $0.862^{* *}$ & $0.948^{* *}$ & $0.959^{* *}$ & $0.960 * *$ & $0.937^{* *}$ & $0.944^{* *}$ & $0.923 * *$ & $0.974^{* *}$ & $0.953 * *$ & $0.958^{* *}$ \\
\hline$\alpha=0.15$ & $0.911^{* *}$ & $0.942^{* *}$ & $0.867^{* *}$ & $0.969^{* *}$ & $0.959^{* *}$ & $0.965^{* *}$ & $0.937^{* *}$ & $0.944^{* *}$ & - & $0.974^{* *}$ & $0.953^{* *}$ & - \\
\hline$\alpha=0.10$ & $0.911^{* *}$ & $0.942^{* *}$ & $0.867^{* *}$ & $0.969^{* *}$ & $0.959^{* *}$ & $0.965^{* *}$ & $0.937^{* *}$ & $0.944^{* *}$ & - & $0.974^{* *}$ & $0.953^{* *}$ & - \\
\hline$\alpha=0.05$ & - & $0.942^{* *}$ & $0.867^{* *}$ & - & $0.959 * *$ & $0.965^{* *}$ & - & $0.944^{* *}$ & - & - & $0.953^{* *}$ & - \\
\hline $\begin{array}{c}\alpha=0.01 \\
\operatorname{DMSFE}(\delta=0.9)\end{array}$ & - & $0.942^{* *}$ & $0.867^{* *}$ & - & $0.959^{* *}$ & $0.965^{* *}$ & - & - & - & - & - & - \\
\hline$\alpha=0.25$ & $0.878^{* *}$ & $0.937^{* *}$ & $0.849^{* *}$ & $0.948^{* *}$ & $0.956^{* *}$ & $0.959^{* *}$ & $0.915^{* *}$ & $0.933^{* *}$ & $0.913^{* *}$ & $0.954^{* *}$ & $0.939^{* *}$ & $0.944^{* *}$ \\
\hline$\alpha=0.20$ & $0.878^{* *}$ & $0.937^{* *}$ & $0.849^{* *}$ & $0.948^{* *}$ & $0.956^{* *}$ & $0.959 * *$ & $0.967^{* *}$ & $0.933^{* *}$ & $0.913^{* *}$ & $0.967^{* *}$ & $0.939^{* *}$ & $0.944^{* *}$ \\
\hline$\alpha=0.15$ & $0.901^{* *}$ & $0.937^{* *}$ & $0.954^{* *}$ & $0.995^{* *}$ & $0.956^{* *}$ & $0.964^{* *}$ & $0.967^{* *}$ & $0.933^{* *}$ & - & $0.967^{* *}$ & $0.939^{* *}$ & - \\
\hline$\alpha=0.10$ & $0.901 * *$ & $0.937^{* *}$ & $0.954^{* *}$ & $0.995^{* *}$ & $0.956^{* *}$ & $0.964^{* *}$ & $0.967^{* *}$ & $0.933^{* *}$ & - & $0.967^{* *}$ & $0.939^{* *}$ & - \\
\hline$\alpha=0.05$ & - & $0.937 * *$ & $0.954^{* *}$ & - & $0.956 * *$ & $0.964^{* *}$ & - & $0.933^{* *}$ & - & - & $0.939 * *$ & - \\
\hline$\alpha=0.01$ & - & $0.937^{* *}$ & $0.954^{* *}$ & - & $0.956 * *$ & $0.964^{* *}$ & - & - & - & - & - & - \\
\hline
\end{tabular}

Notes: *,**,*** indicates rejection of the null hypothesis of equal forecasting accuracy at $10 \%, 5 \%, 1 \%$ 

Authors: Mauro Costantini, Carmine Pappalardo

Title: A Hierarchical Procedure for the Combination of Forecasts

Reihe Ökonomie / Economics Series 240

This is a revised version of Working Paper 228, Economics Series, October 2008, which includes some changes. The most important change regards the reference of Kisinbay (2007), which was not reported in the previous version. The hierarchical procedure proposed in the paper is based on the approach of Kisinbay (2007), but some modifications of that approach are provided

Editor: Robert M. Kunst (Econometrics)

Associate Editors: Walter Fisher (Macroeconomics), Klaus Ritzberger (Microeconomics)

ISSN: $1605-7996$

(C) 2009 by the Department of Economics and Finance, Institute for Advanced Studies (IHS),

Stumpergasse 56, A-1060 Vienna • ㅍㅛㅛ +43 1 59991-0 • Fax +43 159991-555 • http://www.ihs.ac.at 
ISSN: 1605-7996 